\title{
ASSESSMENT OF HOMOGENEOUS NON-EQUILIBRIUM RELAXATION CRITICAL FLOW MODEL
}

\author{
K. Ohkawa \\ Westinghouse Electric Company \\ Nuclear Services Division \\ P. O. Box 355 \\ Pittsburgh, PA. 15230-0355 \\ e-mail: ohkawak@westinghouse.com
}

Keywords: Critical Flow Model, Best Estimate LOCA.

\subsection{INTRODUCTION}

A comprehensive review and assessment of critical flow models were performed previously by Elias and Lellouche (1994). However, a class of critical flow models that is of practical importance was not included in that study. One such model is Homogeneous Non-equilibrium Relaxation Critical Flow Model (HNRM) which belongs to simplified models where one or more non-equilibrium conditions are ignored for modeling ease and computational efficiency. The model assumes equal velocities for the vapor and liquid phases, but considers thermal non-equilibrium between the phases, and is thought to have better characteristics for modeling the subcooled and low quality critical discharge. Unlike other critical flow models currently available in thermal-hydraulic systems codes such as TRAC-PF1/MOD2 and RELAP5/MOD3, this model requires spacial integration of governing equations from the reservoir to the throat assuming that the critical condition exists at the throat. The latest model in this class was developed by Downar-Zapolski et. al, (1996). In

Pressure/Temperature of Upstream Conditions in Critical Flow Test Matrix and ROSA 5\% and LOFT 2.5\% Small Break Tests

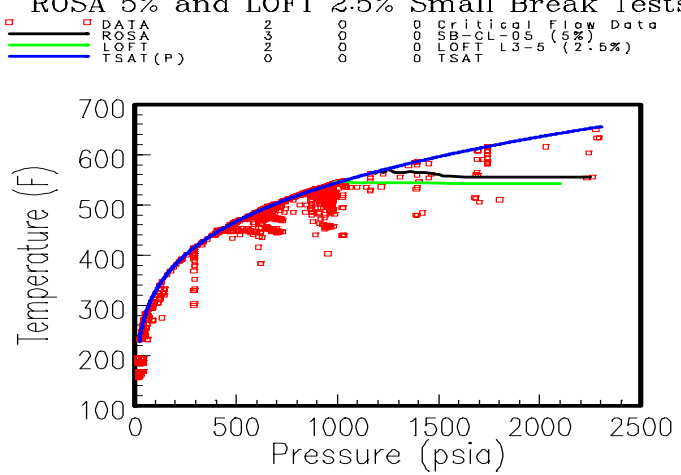

this study HNRM Critical Flow Model was assessed against the full range of critical flow data including the dataset compiled by llic (1986), the Marviken CFT (EPRI-NP-2370, 1982), and data with two-phase upstream condition by Anderson (1986). Prediction accuracy, selected parametric effects of upstream fluid conditions, geometry effects are discussed.

\subsection{ASSESSMENT RESULTS}

The mean error and standard deviation were found to be $-9.7 \%$ and $18.2 \%$ respectively.

Parametric study was conducted to investigate the trend and stability of the predictions. The results indicated that there are minor trend relative to pressure while significant trends were found relative to $L / D, L$, and inlet quality. The model was found to be numerically stable (node size and choke criterion), however it appears to require that the flow quality to be non-zero and less than 1.

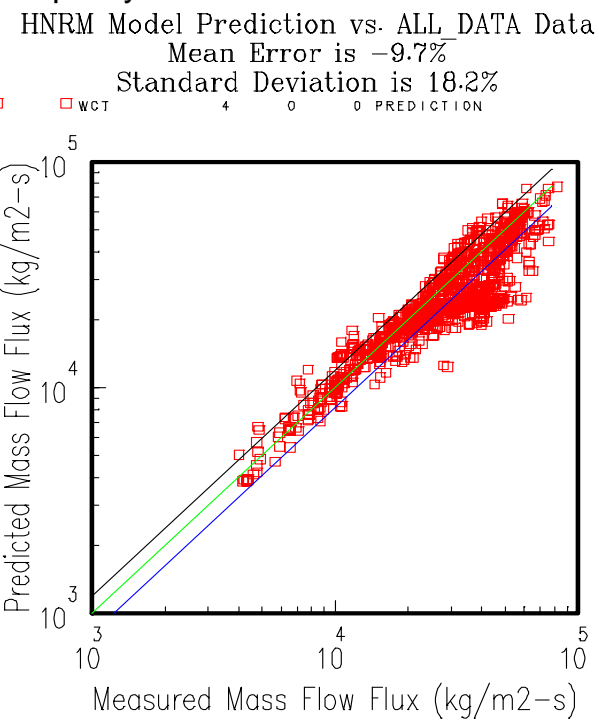

Copyright $\odot 2007$ by JSME 


\title{
ASSESSMENT OF HOMOGENEOUS NON-EQUILIBRIUM RELAXATION CRITICAL FLOW MODEL
}

\author{
K. Ohkawa \\ Westinghouse Electric Company \\ Nuclear Services Division \\ P. O. Box 355 \\ Pittsburgh, PA. 15230-0355 \\ e-mail: ohkawak@westinghouse.com
}

Keywords: Critical Flow Model, Best Estimate LOCA.

\section{ABSTRACT}

A comprehensive review and assessment of critical flow models were performed previously by Elias and Lellouche (1994). However, a class of critical flow models that is of practical importance was not included in that study. One such model is Homogeneous Non-equilibrium Relaxation Critical Flow Model which belongs to simplified models where one or more non-equilibrium conditions are ignored for modeling ease and computational efficiency. The model assumes equal velocities for the vapor and liquid phases, but considers thermal non-equilibrium between the phases, and is thought to have better characteristics for modeling the subcooled and low quality critical discharge. Unlike other critical flow models currently available in thermal-hydraulic systems codes such as TRAC-PF1/MOD2 and RELAP5/MOD3, this model requires spacial integration of governing equations from the reservoir to the throat assuming that the critical condition exists at the throat. The latest model in this class was developed by Downar-Zapolski et. al, (1996). In this study their Homogeneous Non-equilibrium Relaxation Critical Flow Model was assessed against the full range of critical flow data including the dataset compiled by Ilic (1986), the Marviken CFT (EPRI-NP-2370, 1982), and data with two-phase upstream condition by Anderson (1986). Prediction accuracy, selected parametric effects of upstream fluid conditions, geometry effects are discussed.

\subsection{INTRODUCTION}

The critical flow model in Thermal-Hydraulic System codes such as TRAC-PF1/MOD2 (1992), WCOBRA/TRAC (Bajorek, 1998), RELAP5/MOD3 (1995) which are used to analyze LOCAs use a combination of several critical flow models depending on the fluid condition at the upstream of the break, i.e., Abuaf-Jones-Wu model (Jones,1980, Abuaf, 1983) for subcooled discharge, the PF1 or RELAP5 method of characteristic model for two-phase discharge. The transition between the two regimes is accomplished by linearly interpolating the two models over two end $\alpha$ values. These two arbitrarily selected end points obviously impact the quality of predictions. In case of Henry-Fauske model for example, this transition is selected based on the upstream quality. Comparison of Henry-Fauske model prediction to Marviken test data reveals that when this selection fails, the prediction and the data may show gross deviation as seen in Figure 1.

Henry-Fauske Model Prediction vs. Marviken_6 Data
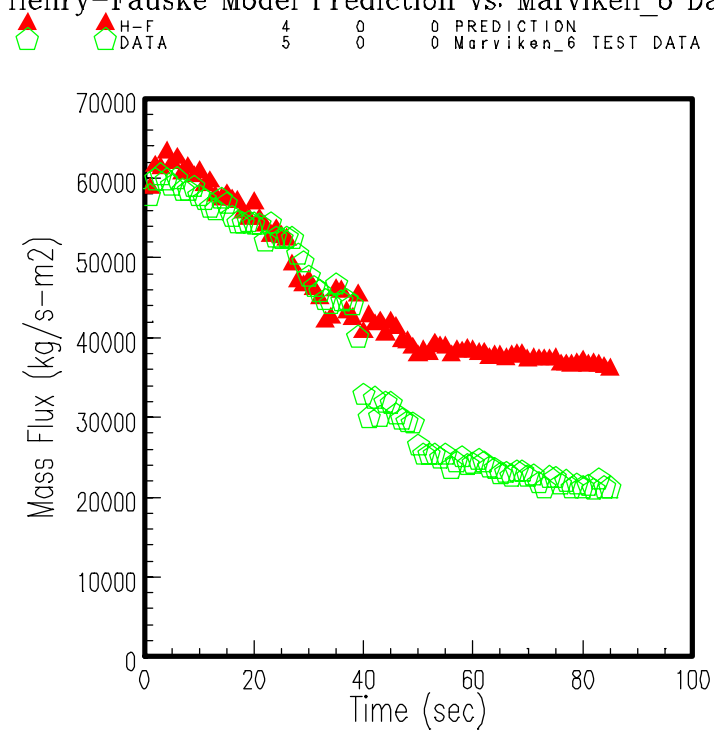

Figure 1: Henry-Fauske Applied to Marviken Test 6 
It is therefore desirable to employ a more mechanistic critical flow model to accurately predict transients with a prolonged critical flow period such as seen in small Break LOCAs (Brown, 2000).

Homogeneous Non-equilibrium Relaxation Model (HNRM) suggested by Bauer (1976), Bilicki (1990), Feburie (1993), and Downar-Zapolski (1996) addresses this transition region by explicitly modeling the relaxation associated with the delay in flashing of superheated liquid. The model assumes that phase slip in this transition region is of the second order and is neglected. Downar-Zapolski's model is used for the assessment. The governing equation set is discussed next.

\subsection{MATHEMATICAL MODEL FOR HOMOGENEOUS NON-EQUILIBRIUM RELAXATION CRITICAL FLOW MODEL}

This class of critical flow models are based on the following assumptions:

1. Steady State

2. Homogeneous model (equal velocity):

3. Non-equilibrium (thermal non-equilibrium):

Liquid could either be subcooled, saturated or superheated while vapor is always saturated.

In HNRM suggested by Downar-Zapolski, the following set of four governing equations is solved along the break flow path. Note that the non-equilibrium flow quality is positive if the flow is two phase even when the liquid is subcooled.

Mass conservation equation:

$\frac{1}{U} \cdot \frac{d U}{d Z}=\frac{1}{v_{m}} \cdot\left\{X \cdot \frac{d v_{g}}{d P}+(1-X) \cdot\left(\frac{\partial v_{l}}{\partial P}\right) T_{l}\right\} \cdot \frac{d P}{d Z}+$

$\frac{v_{g}-v_{l}}{v_{m}} \cdot \frac{d X}{d Z}+\frac{1-X}{v_{m}} \cdot\left(\frac{\partial v_{l}}{\partial T}\right)_{P} \cdot \frac{d T_{l}}{d Z}$

Momentum conservation equation:

$$
\frac{U}{v_{m}} \cdot \frac{d U}{d Z}=-\left(\frac{d P}{d Z}\right)-\left(\frac{d P}{d Z}\right)_{F R}+\frac{g}{v_{m}}
$$

Energy conservation equation:

$$
\begin{aligned}
& \left\{X \cdot \frac{d h}{d P}+(1-X) \cdot\left(\frac{\partial h_{l}}{\partial P}\right) T_{l}\right\} \cdot \frac{d P}{d Z}+ \\
& \left(h_{g}-h_{l}\right) \cdot \frac{d X}{d Z}+(1-X) \cdot\left(\frac{\partial h_{l}}{\partial T}\right)_{P} \cdot \frac{d T_{l}}{d Z}+ \\
& U \cdot \frac{d U}{d Z}=0
\end{aligned}
$$

The fourth equation is a vapor mass conservation equation, and describes the phase transition or the flashing interfacial heat transfer. When the liquid is subcooled, the fourth equation specifies that there are no phase transition, as,

$$
\frac{d X}{d Z}=0 \quad \text { for } T_{l}<T_{\text {sat }}
$$

The liquid phase becomes superheated as the pressure decreases along the flow channel. The desuperheating occurs due to flashing. The HNRM explicitly specifies the vapor generation rate, as seen below,

$$
\begin{aligned}
U \cdot \frac{d X}{d Z}=\frac{\Gamma_{g}}{\rho_{m}}=\frac{X_{e}-X}{\Theta}=(1-X) & \cdot \frac{h_{l}-h_{f}}{h_{g}-h_{f}} \cdot \frac{1}{\Theta} \text { for } T_{l} \geq T_{\text {sat }} \\
\text { where, for P } \geq 10 \text { bar } \quad \Theta & =\Theta_{0} \cdot \alpha^{-0.54} \cdot \varphi^{-1.76} \\
\varphi & =\frac{P_{\text {sat }}\left(T_{l}\right)-P}{P_{c}-P_{\text {sat }}{ }^{\left(T_{l}\right)}} \\
\Theta_{0} & =3.84 \times 10^{-7} \text { sec } \\
\Theta & =\Theta_{0} \cdot \alpha^{-0.257} \cdot \psi^{-2.24} \\
\Psi & =\frac{P_{\text {sat }}\left(T_{l}\right)-P}{P_{\text {sat }}{ }^{\left(T_{l}\right)}} \\
\text { and, for P } \geq 10 \text { bar } \quad & =6.51 \times 10^{-4} \text { sec } \quad \text { Eq.(5) }
\end{aligned}
$$

where, $\mathrm{h}$ is the specific enthalpy, $\mathrm{P}$ is the pressure, $\mathrm{T}$ is the temperature, $\mathrm{U}$ is the mixture velocity, $\mathrm{V}$ is the specific volume, $X$ is the quality, and subscripts I, g, m, f signify liquid, vapor and mixture, and saturation, respectively.

This model lacks an explicit flashing delay model found in Homogeneous Non-equilibrium Model by Amos and Schrock (1984) and Lee and Schrock (1990). However, the relaxation parameter determined from Reocruex's data (1974) and defined as a function of void fraction and pressure effectively acts to delay the nucleation and flashing. Note that the relaxation parameter seen in the above equation is equivalent to specifying the interfacial heat transfer coefficient for superheated liquid since $h_{1}-h_{f}$ can be written as $C_{p}\left(T_{1}-T_{f}\right)$.

The explicit form of Colebrook-White model was used for the single phase friction factor. The two phase multiplier is taken from Levy (1960) in stead of Richardson's which was suggested in the original HNRM.

\subsection{VALIDATION DATABASE}

Ilic et al. (1986) compiled a list of qualified critical flow dataset from previous work. The dataset was further examined for selection for the validation purposed. Dataset without well defined stagnation condition or upstream condition were excluded at this time. Dataset by Cruver (1963), Fauske (1962), Henry (1970), Isbin (1957) and Zaloudek 
(1964) do not report stagnation pressure. Dataset by Guizovarn (1975) contains superheated liquid upstream of the nozzle which is contrary to the test description which states subcooled inlet condition. Dataset by Bryers and Hsieh (1966) contains highly subcooled stagnation condition contrary to the description. The dataset by Ogasawara (1969) did not contain the reservoir temperature or the quality. Datasets by Danforth (1941) and Schrock \& Starkman (1977) are suspect with regard to achieving the critical condition according to llic et al. (1986). Dataset by Morrison (1977) appears to be inconsistent with other similar data.

Pressure/Temperature of Upstream Conditions in Critical Flow Test Matrix and ROSA 5\% and LOFT 2.5\% Small Break Tests
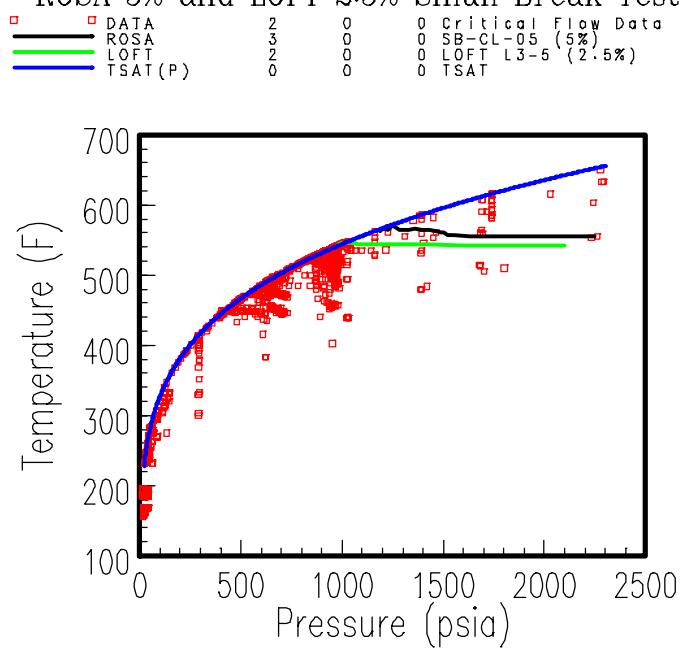

Figure 2: Upstream Temperature and Pressure
These dataset mentioned above need to be further investigated since as-reported upstream condition is suspect for the validation work. Table 3.1 contains all selected dataset for this study. The dataset represents more than 1400 points from 40 geometries, containing data from 13 to 2500 psia. The geometry ranges from $0<\mathrm{L}<2300 \mathrm{~mm}$, $0.464 \mathrm{~mm}<\mathrm{D}_{\mathrm{H}}<500 \mathrm{~mm}$. The upstream conditions of combined $V \& V$ data are shown graphically in Figures 2 and 3 together with the pressure/temperature trajectories of the primary system of LOFT and ROSA during small break LOCA experiments for comparison.

Quality/Pressure of Upstream Conditions in Critical Flow Test Maxtrix DATA $\underset{3}{ }$ Quality $=(\mathrm{V}-\mathrm{VF}) / \mathrm{VFG}$

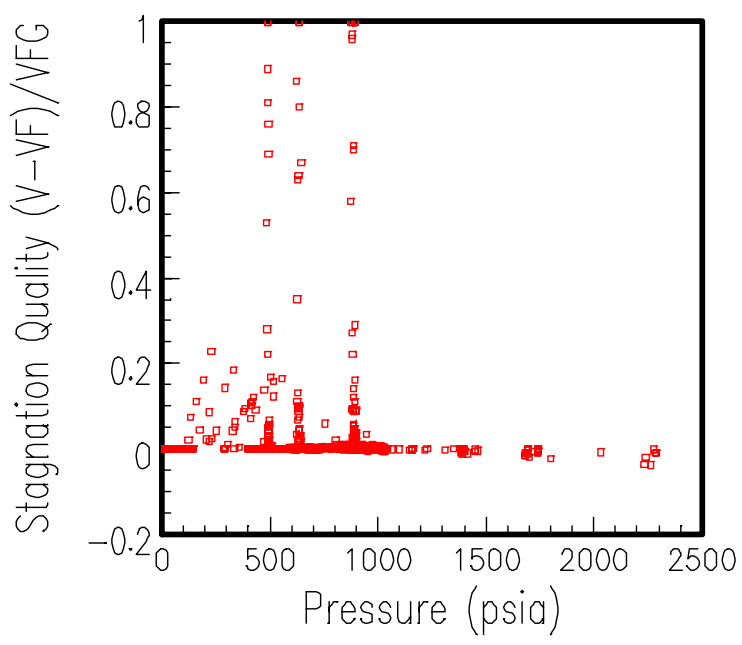

Figure 3: Upstream Quality

Table 3.1: Validation Dataset and Upstream Condition and Geometry Parameter Range

\begin{tabular}{|l|l|l|l|l|l|}
\hline Reference & $\begin{array}{l}\text { Pressure } \\
\text { (psia) }\end{array}$ & Upstream Condition & Points & Length (mm) & Dhyd (mm) \\
\hline \hline Ardron (1978) & $22-55$ & Subcool & 32 & 1015 & 26.3 \\
\hline Boivin (1979) & $200-1500$ & Subcool & 21 & $500-1830$ & $12-50$ \\
\hline Fincke (1981) & $13-45$ & Subcool & 92 & 79.72 & 18.28 \\
\hline Jeandey (1981) & $100-2100$ & Subcool & 88 & 463 & 20.13 \\
\hline Neusen (1969) & $100-600$ & Saturated (0.0 $\leq x \leq 0.23)$ & 37 & 0 & $6.4-11.125$ \\
\hline Reocreux (1974) & 3050 & Subcool & 28 & 2335 & 20 \\
\hline Seynhaeve (1980) & $40-150$ & Subcool & 57 & $221-306$ & 12.5 \\
\hline Sozzi \& Sutherland (1975) & $400-1100$ & Subcool and Saturated & 667 & $4.7-1822.5$ & 12.7 \\
\hline Marviken (1982) & $400-750$ & Subcool and Saturated & 252 & $150-300$ & $300-500$ \\
\hline Amos \& Schrock (1983) & $500-2300$ & Subcool & 44 & 63.5 & $0.464-0.748$ \\
\hline Anderson (1986) & $500-900$ & Saturated (0.0 $\leq x \leq 1.0)$ & 109 & 54 & 16.2 \\
\hline All Data & $13-2300$ & $\begin{array}{l}\text { Subcooled Liquid to Satu- } \\
\text { rated Single Phase Vapor }\end{array}$ & 1427 & $0-2335$ & $0.418-500$ \\
\hline
\end{tabular}

a. Only 2 shortest nozzle tests, Tests 6, 7, 23, and 24 (Nozzles 2 and 6) are used. 


\subsection{MODEL PREDICTIONS}

\subsection{Numerical Model}

The governing equations shown in Equations 1 to 5 were integrated along the flow path with Runge-Kutta method. The flow path was divided into 101 equal length nodes. The shooting method is then used to find the critical velocity. The choking is assumed to occur at the exit, and the criterion for choking is $\mathrm{dP} / \mathrm{dZ}<-10^{9}(\mathrm{~Pa} / \mathrm{m})$. The initial inlet mass flux is iterated until this condition is reached at the flow channel exit as seen in the figure below.
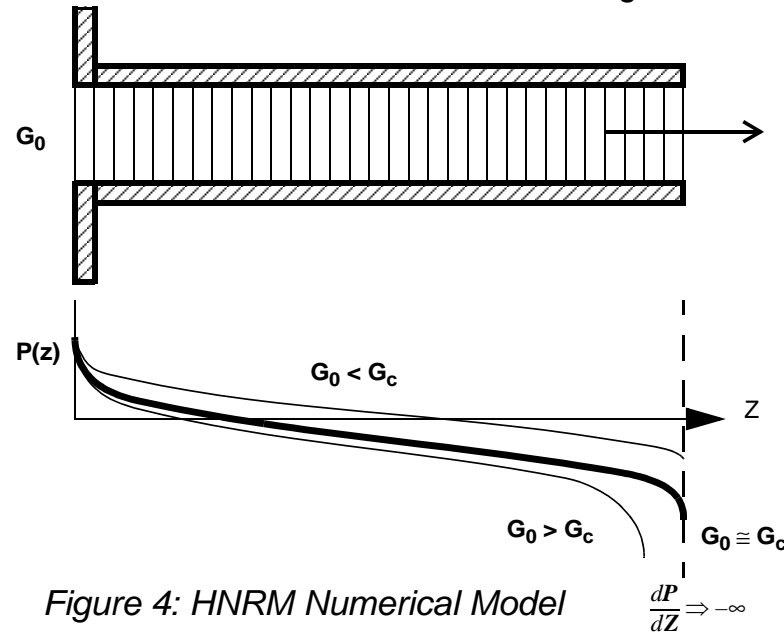

$\mathrm{G}_{0}$, is the inlet mass flux which is iterated to yield $\mathrm{dP} / \mathrm{dZ}$ at the throat of $-1.0 \times 10^{9} \mathrm{~Pa} / \mathrm{m}$ or below. When $G_{0}$ is lower than the critical mass flux, $G_{c}$, the pressure gradient at the exit does not reach the criterion. When $G_{0}$ is higher than $G_{c}$, singular point is reached before the exit.

The two phase friction multiplier was changed from Richardson's model which was used by Downar-Zapolski et al. (1996) to Levy's model for high quality flow considerations. Levy's model is expressed as,

$$
\phi_{\text {lo }}^{2}=\left(\frac{1-x}{1-\alpha}\right)^{1.75}
$$

Figure 5 shows the TPFL (Anderson, 1986) 500 psia data and the critical flow prediction with Richardson's and Levy's two-phase friction multiplier. TPFL data is the only dataset which has the inlet quality range of zero to unity. It is clear that at higher quality $(x>0.5)$, Levy's model shows the correct trend while Richardson's model approaches zero linearly as the quality approaches unity.

Figure 5 also shows that HNRM appears to be deficient at or near single phase steam inlet condition. These data points (total of 9 ) at or near $x=1.0$ were removed from the model assessment which will be discussed in the next section.

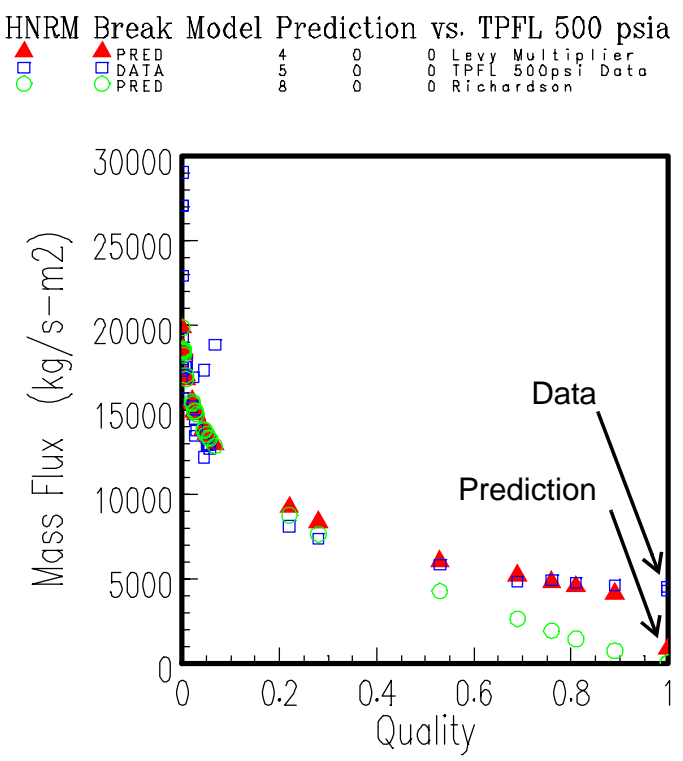

Figure 5: Two Phase Friction Multiplier and Single Phase Steam data points

In case of an orifice $(L=0 \mathrm{~mm}$ in the case of Neusen), the channel length of $1 \mathrm{~mm}$ was assumed in the HNRM model integration.

\subsection{Results}

\subsubsection{Overall Prediction vs. Data}

Model predictions and the comparison to all datasets are shown in Table 4.1. The mean error in subcooled region was found to be $-5.4 \%$ and the standard deviation was found to be $15.0 \%$. The mean error in saturated region was found to be $-15.3 \%$ and the standard deviation was found to be $20.5 \%$. The mean error for the entire dataset (1418 points) was found to be $-9.7 \%$ and the standard deviation was found to be $18.2 \%$. Figure 6 shows the comparison of model prediction against all data points (except for the points at or near single phase vapor).

Table 4.1: Critical Flow Data Comparison for Homogeneous Non-equilibrium Relaxation Critical Flow Model

\begin{tabular}{|c|c|c|c|c|c|c|c|}
\hline $\begin{array}{l}\text { Dat } \\
\text { a } \\
\text { No. }\end{array}$ & Dataset Reference per Geometry & $\begin{array}{l}\mathrm{L} \\
(\mathrm{mm})\end{array}$ & \begin{tabular}{|l}
$\mathrm{D}$ \\
$(\mathrm{mm})$
\end{tabular} & $\cos \theta$ & \begin{tabular}{|l} 
N-Dat \\
$\mathrm{a}$
\end{tabular} & $\frac{\text { Mean Error } \mathcal{E}(\%)}{\left(\frac{G_{c, \text { calc }}-G_{c, \text { meas }}}{G_{c, \text { meas }}}\right)}$ & $\sigma(\varepsilon)(\%)$ \\
\hline 1 & Ardron, K. H. \& Ackerman, M. C. (1978) & 1015 & 26.3 & 0 & 32 & 4.4 & 11.2 \\
\hline
\end{tabular}


Table 4.1: Critical Flow Data Comparison for Homogeneous Non-equilibrium Relaxation Critical Flow Model

\begin{tabular}{|c|c|c|c|c|c|c|c|}
\hline $\begin{array}{l}\text { Dat } \\
\text { a } \\
\text { No. }\end{array}$ & Dataset Reference per Geometry & $\begin{array}{l}\mathrm{L} \\
(\mathrm{mm})\end{array}$ & $\begin{array}{l}\mathrm{D} \\
(\mathrm{mm})\end{array}$ & $\cos \theta$ & $\begin{array}{l}\text { N-Dat } \\
\mathrm{a}\end{array}$ & $\frac{\text { Mean Error } \mathcal{E}(\%)}{\left(\frac{G_{c, \text { calc }}-G_{c, \text { meas }}}{G_{c, \text { meas }}}\right)}$ & $\sigma(\varepsilon)(\%)$ \\
\hline 12 & \begin{tabular}{|l|} 
Boivin (1979) \\
\end{tabular} & 500 & 12 & 0 & 10 & 9.2 & 2.8 \\
\hline 13 & \begin{tabular}{|l|} 
Boivin (1979) \\
\end{tabular} & 1600 & 30 & 0 & 5 & 0.6 & 23.5 \\
\hline 14 & Boivin (1979) & 1700 & 50 & 0 & 6 & -13.8 & 7.3 \\
\hline 18 & Fincke \& Collins (1981) & 13 & 44 & 0 & 92 & 5.3 & 3.4 \\
\hline 33 & Jeandey et al. (1981) & 463 & 20 & 1 & 15 & -0.8 & 9.4 \\
\hline 34 & Jeandey et al. (1981) & 463 & 20 & 1 & 73 & $\mid-10.1$ & 11.3 \\
\hline 37 & Neusen (1969) & 0 & 11 & 0 & 25 & 31.2 & 13.5 \\
\hline 38 & \begin{tabular}{|l} 
Neusen (1969) \\
\end{tabular} & 0 & 6 & 0 & 12 & 12.0 & 14.8 \\
\hline 40 & Reocreux (1974) & 2335 & 20 & 1 & 28 & -4.5 & 6.3 \\
\hline 41 & \begin{tabular}{|l} 
Seynhaeve (1980) \\
\end{tabular} & 306 & 13 & 1 & 26 & -7.7 & 5.1 \\
\hline 42 & Seynhaeve (1980) & 306 & 13 & 1 & 31 & -6.1 & 6.7 \\
\hline 45 & Sozzi \& Sutherland (1975) & 45 & 12.7 & 0 & 128 & $\mid-23.9$ & 15.1 \\
\hline 46 & Sozzi \& Sutherland (1975) & 45 & 12.7 & 0 & 13 & -40.5 & 9.6 \\
\hline 47 & Sozzi \& Sutherland (1975) & 57 & 12.7 & 0 & 47 & -31.2 & 6.3 \\
\hline 48 & Sozzi \& Sutherland (1975) & 362 & 12.7 & 0 & 19 & 7.1 & 6.2 \\
\hline 49 & Sozzi \& Sutherland (1975) & 83 & 12.7 & 0 & 17 & -15.1 & 13.0 \\
\hline 50 & Sozzi \& Sutherland (1975) & 553 & 12.7 & 0 & 13 & -0.9 & 10.0 \\
\hline 51 & Sozzi \& Sutherland (1975) & 108 & 12.7 & 0 & 23 & 1.3 & 9.9 \\
\hline 52 & Sozzi \& Sutherland (1975) & 679 & 12.7 & 0 & 96 & 17.5 & 11.5 \\
\hline 53 & Sozzi \& Sutherland (1975) & 159 & 12.7 & 0 & 15 & -11.1 & 13.1 \\
\hline 54 & Sozzi \& Sutherland (1975) & 1823 & 12.7 & 0 & 81 & 15.6 & 13.5 \\
\hline 55 & Sozzi \& Sutherland (1975) & 235 & 12.7 & 0 & 12 & -6.8 & 3.7 \\
\hline 56 & Sozzi \& Sutherland (1975) & 273 & 12.7 & 0 & 22 & -20.8 & 4.8 \\
\hline 57 & Sozzi \& Sutherland (1975) & 5 & 12.7 & 0 & 58 & -10.0 & 15.7 \\
\hline 58 & Sozzi \& Sutherland (1975) & 322 & 12.7 & 0 & 24 & -1.7 & 7.9 \\
\hline 59 & Sozzi \& Sutherland (1975) & 513 & 12.7 & 0 & 24 & 7.7 & 7.4 \\
\hline 60 & Sozzi \& Sutherland (1975) & 640 & 12.7 & 0 & 17 & 7.0 & 7.9 \\
\hline 61 & Sozzi \& Sutherland (1975) & 195 & 12.7 & 0 & 23 & -18.7 & 5.2 \\
\hline 62 & Sozzi \& Sutherland (1975) & 45 & 19 & 0 & 23 & -27.8 & 6.5 \\
\hline 63 & Sozzi \& Sutherland (1975) & 732 & 54 & 0 & 4 & -17.7 & 2.5 \\
\hline 64 & Sozzi \& Sutherland (1975) & 696 & 76 & 0 & 3 & -8.8 & 3.3 \\
\hline 65 & Sozzi \& Sutherland (1975) & 63 & 28 & 0 & 5 & $\mid-18.2$ & 3.5 \\
\hline 69 & Marviken Test 6 (1982) & 300 & 300 & -1 & 85 & -11.8 & 9.4 \\
\hline 70 & Marviken Test 7 (1982) & 300 & 300 & -1 & 84 & $\mid-18.2$ & 7.9 \\
\hline 71 & Marviken Test 23 (1982) & 150 & 500 & -1 & 44 & -8.6 & 10.0 \\
\hline 72 & Marviken Test 24 (1982) & 150 & 500 & -1 & 39 & -21.1 & 12.0 \\
\hline 73 & Amos \& Schrock (1983) & 63.5 & 0.748 & -1 & 18 & 0.8 & 7.8 \\
\hline 74 & Amos \& Schrock (1983) & 63.5 & 0.464 & -1 & 26 & -0.2 & 9.6 \\
\hline 75 & Anderson \& Benedetti (1985) & 31.9 & 16.2 & 0 & $\begin{array}{l}100^{\mathrm{a}} \\
(109)\end{array}$ & 1.2 & 15.7 \\
\hline \multicolumn{5}{|c|}{ TOTAL } & 1418 & $\mid-9.7$ & 18.2 \\
\hline
\end{tabular}

\section{a. 9 points from this dataset were not used for comparison.}

\subsubsection{Possible Deficiency}

When applying the model to inlet fluid condi- tions at or near the single phase vapor, the model appears to be deficient. A combination with other model may be required with some care. 


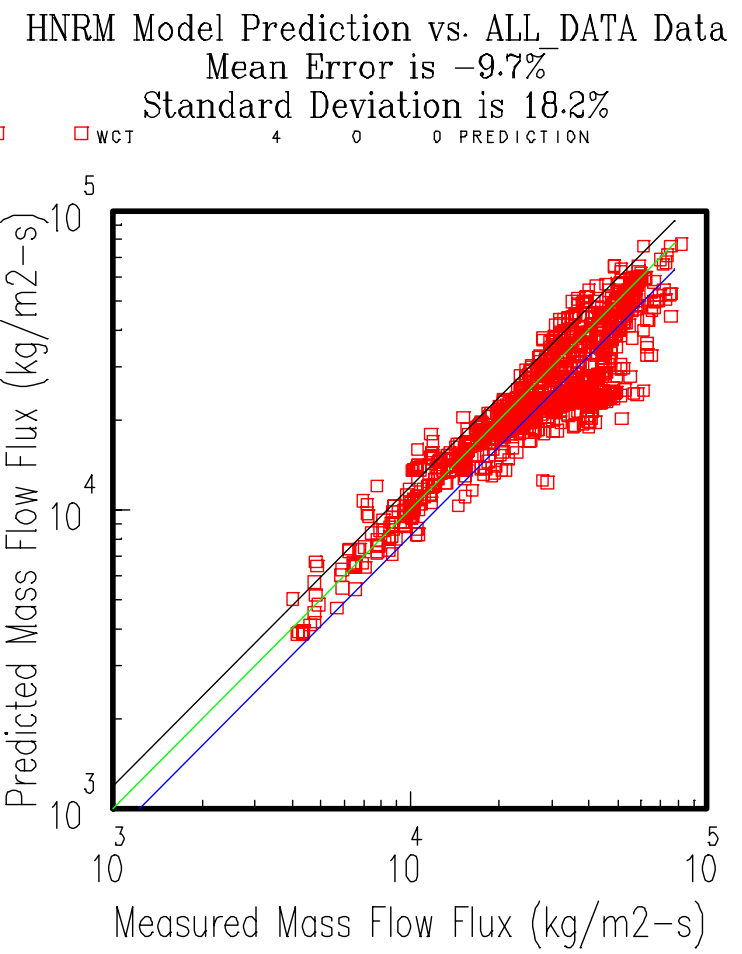

Figure 6: HNRM Predicted vs. Measured for All Data Points

\subsubsection{Model Prediction Trend with respect to Pressure}

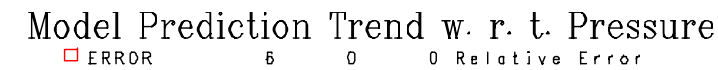

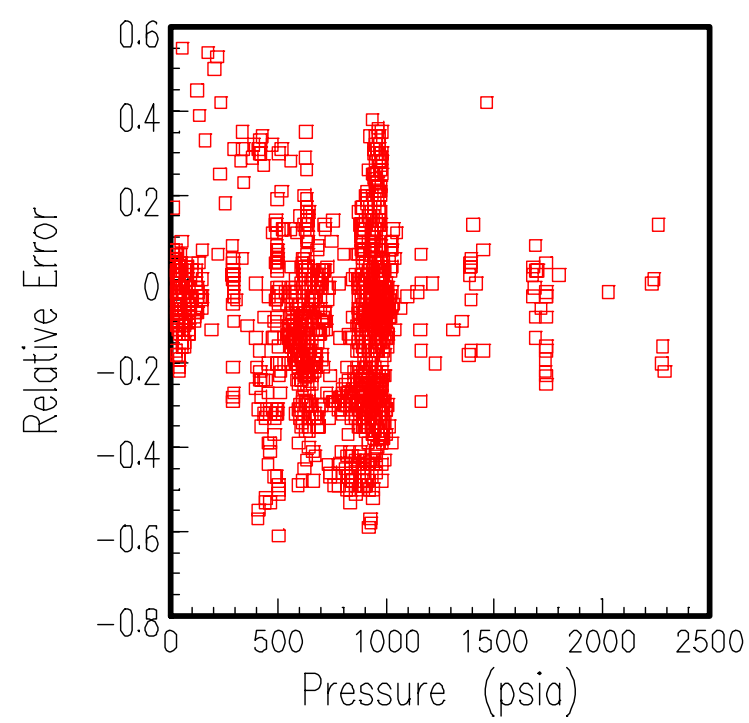

Figure 7: Inlet Pressure Effect

A possible model trend with respect to the upstream pressure is examined. Figure 7 shows the error vs. pressure of all data points. The figure does not show global trend relative to the upstream pressure above 300 psia. Below 300 psia there are a cluster of points with over-prediction as high as $60 \%$. Figure 7 also shows that there is larger spread in the lower pressure points $(P<1000$ psia).

\subsubsection{Model Prediction Trend with respect to Quality}

A possible model trend with respect to the upstream quality is examined. Figures $8 \mathrm{a}$ and $8 \mathrm{~b}$

Model Prediction Trend w. r. t. Quality
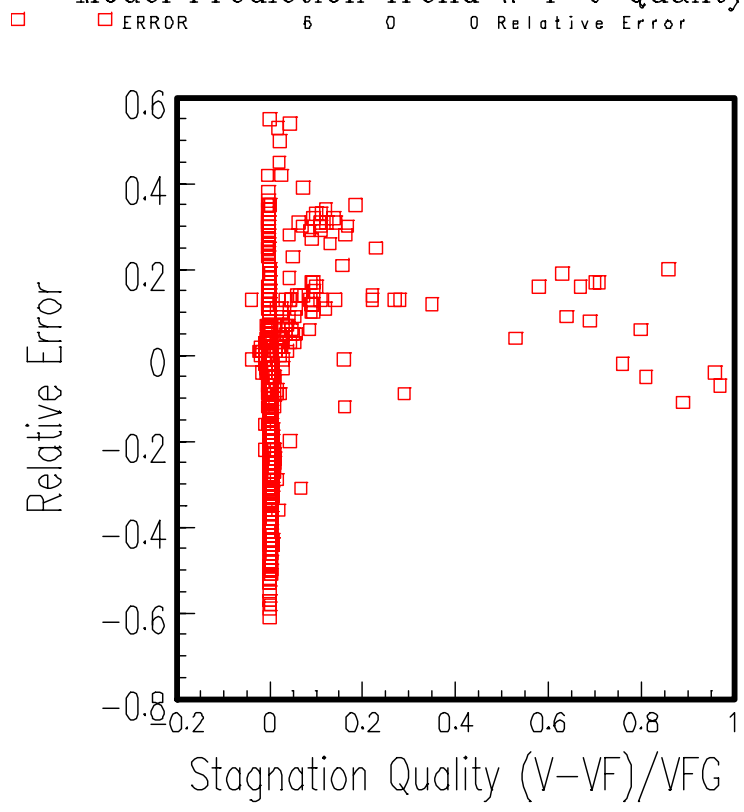

Figure 8a: Inlet Quality Effect

Model Prediction Trend w. r. t. Quality

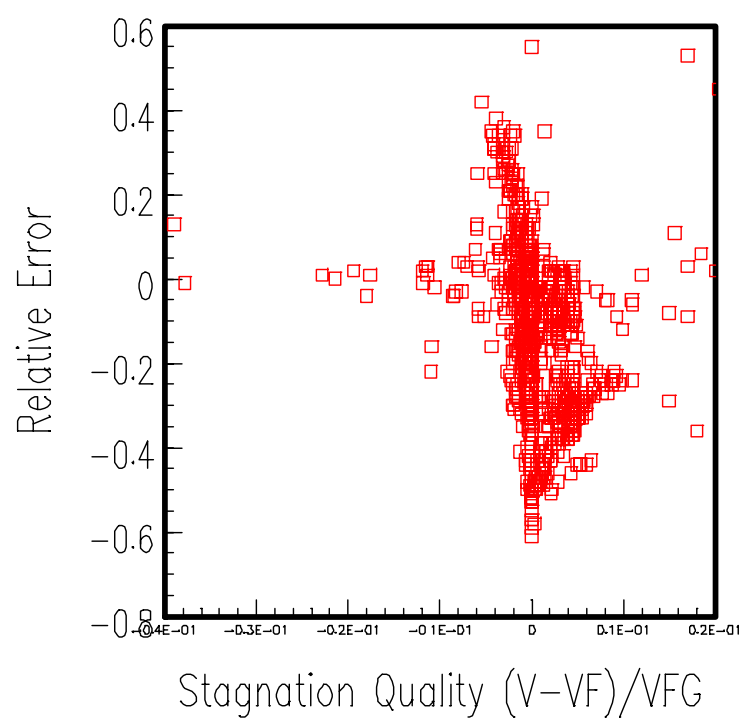

Figure 8b: Inlet Quality Effect

shows the error vs. quality of all data points. Figure 
$8 \mathrm{a}$ spans quality of 0 to 1 while Figure $8 \mathrm{~b}$ focused on the subcool liquid through very low quality two-phase condition. These figures show global trend relative to the upstream quality. The model tends to underpredict the critical mass flux for very low quality two-phase flows, and overpredict in the two-phase region. Near single phase vapor region, the model's overprediction becomes somewhat smaller.

\subsubsection{Model Prediction Trend with respect to Channel Length}

A possible model trend with respect to the channel length is examined. Figures $9 a$ and $9 b$

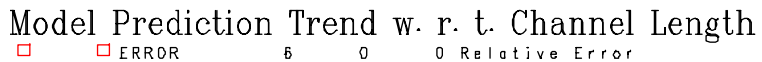

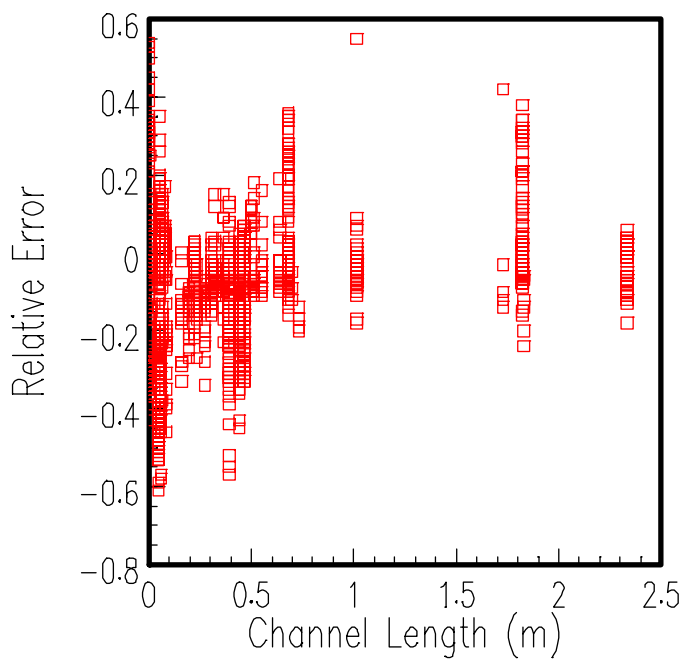

Figure 9a: Impact of Break Flow Path Length

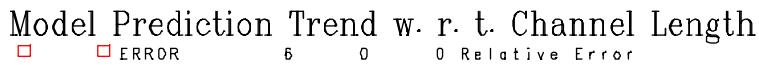

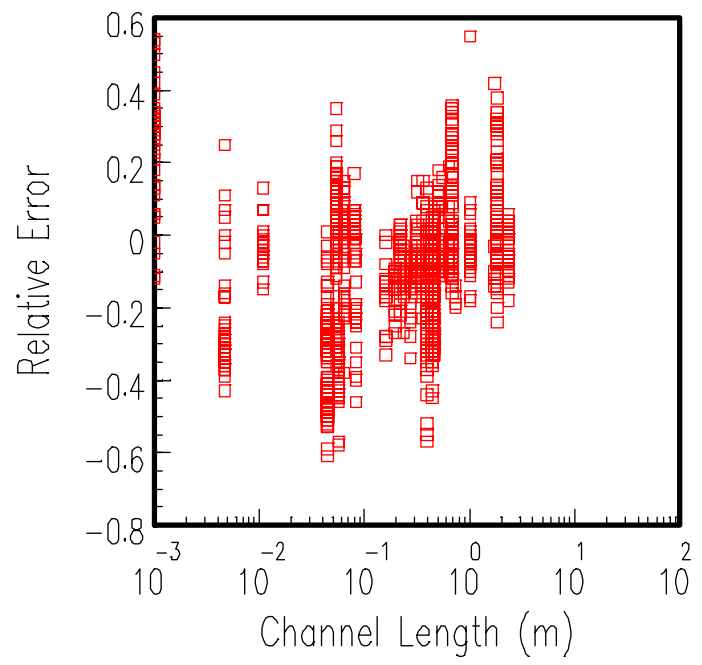

Figure 9b: Impact of Break Flow Path Length show the error vs. channel length for all data points. The figures show global trend relative to the channel length. Figures also show that there is larger spread in the short length nozzle predictions.

The worst under-prediction by model is seen at a channel length of $\sim 5 \mathrm{~cm}$. Below $5 \mathrm{~cm}$, under-prediction by the model tends to decrease and at the channel length of $\sim 1 \mathrm{~mm}$, the model tends to over-predict.

\subsubsection{Model Prediction Trend with respect to Channel Hydraulic Diameter}

A possible model trend with respect to the hydraulic diameter is examined. Figure 10 shows the error vs. hydraulic diameter of all data points. The figure does not show global trend relative to the hydraulic diameter.

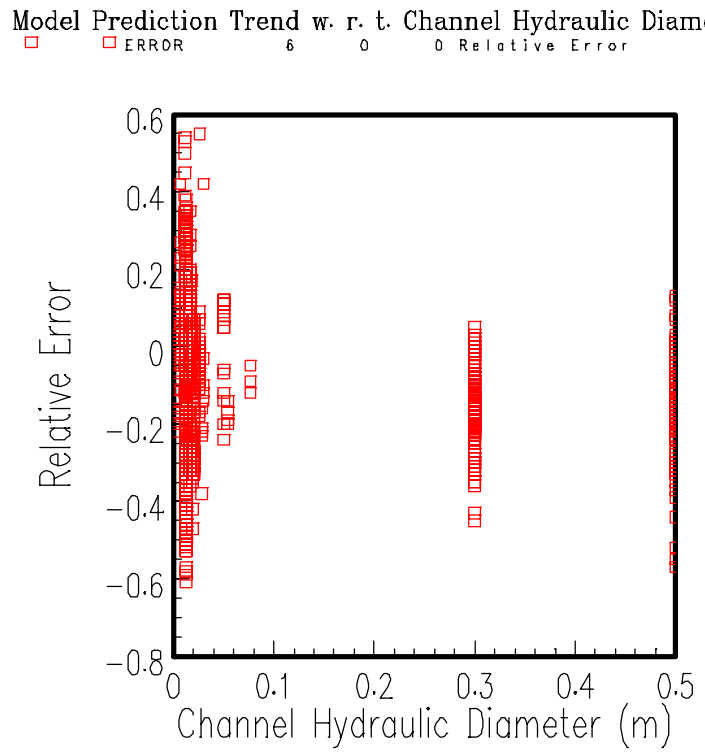

Figure 10: Impact of Hydraulic Diameter

There is a slight tendency to underpredict for large diameter nozzles.

\subsubsection{Model Prediction Trend with respect to Channel L/D}

A possible model trend with respect to the L/D of the break flow path is examined. Figures 11a and $11 \mathrm{~b}$ show the error vs. L/D of all data points. Figure 11a (linear scale comparison) does not reveal global trend relative to the L/D. However, the logarithmic scale comparison in Figure $11 \mathrm{~b}$ shows clearly the model prediction trend relative to L/D.

Flgure $11 \mathrm{~b}$ shows more clearly the trend of prediction relative to channel L/D. The worst under-prediction by model appears to be at L/D of 2. Below L/D of 2, the magnitude of under-prediction decreases as L/D decreases. Below L/D of 
$\sim 0.1$, the model tended to over-predict. Model Prediction Trend w. r. t. Channel L/D

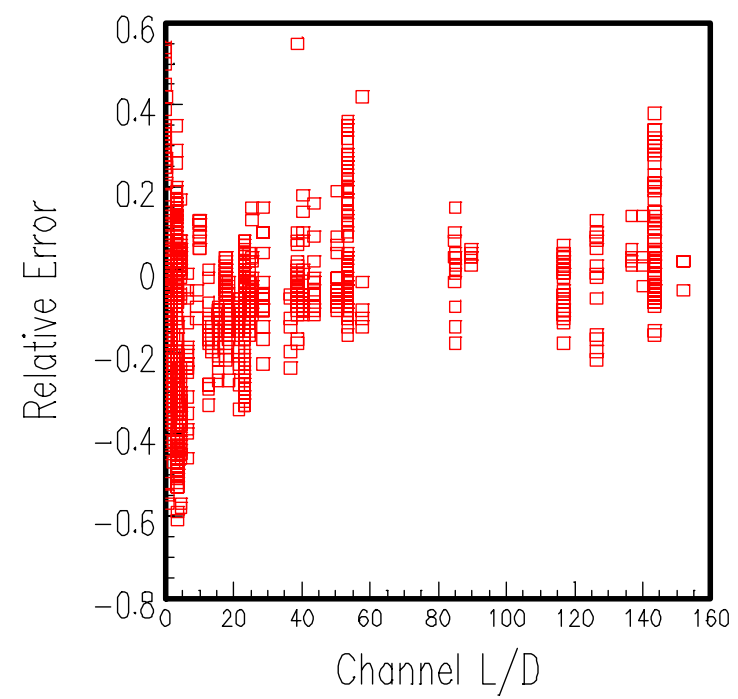

Figure 11a: Impact of Break Flow Path L/D

Model Prediction Trend w. r. t. Channel L/D

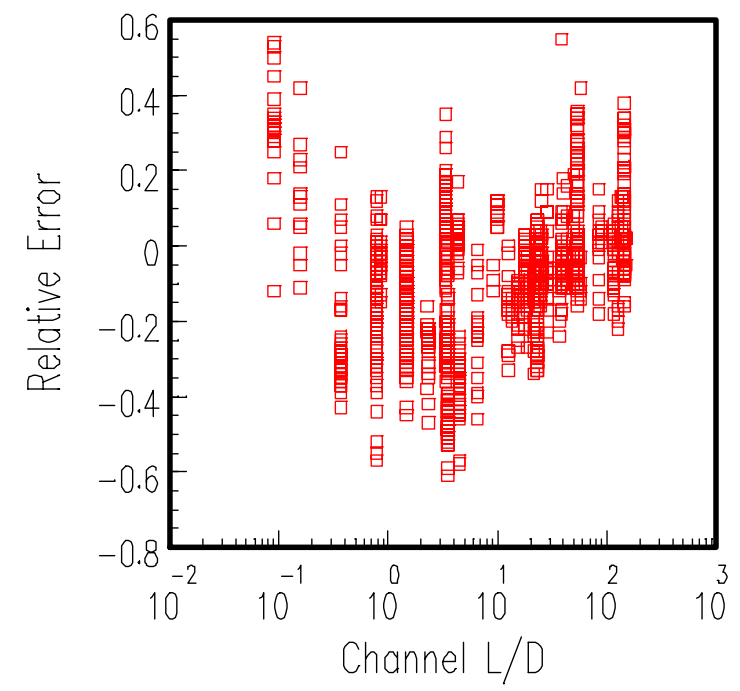

Figure 11b: Impact of Break Flow Path L/D

\subsubsection{Influence of Spacial Discretization}

The model prediction's sensitivity to a number of axial nodes used in the Break Flow Path was investigated in this section. A number of axial nodes, NMAX, is set to 101 for the reference $V \& V$ case. NMAX value was varied from 5 to 401 to investigate the influence on the model prediction.
The result is shown below.

Table 4.2: Prediction sensitivity to Spacial Discretization

\begin{tabular}{|l|l|l|l|}
\hline & \multicolumn{3}{|l|}{ Bias/Standard Deviation (\%) } \\
\hline NMAX & Subcooled & Saturated & Total \\
\hline 5 & $2.5 / 20.9$ & $-9.8 / 22.7$ & $-2.8 / 22.5$ \\
\hline 11 & $-3.4 / 16.1$ & $-13.8 / 20.9$ & $-7.9 / 19.0$ \\
\hline 21 & $-4.8 / 15.1$ & $-14.7 / 20.7$ & $-9.1 / 18.4$ \\
\hline 51 & $-5.3 / 15.1$ & $-15.2 / 20.6$ & $-9.5 / 18.3$ \\
\hline 101 & $-5.4 / 15.0$ & $-15.3 / 20.5$ & $-9.7 / 18.3$ \\
\hline 201 & $-5.5 / 15.0$ & $-15.3 / 20.5$ & $-9.8 / 18.3$ \\
\hline 401 & $-5.6 / 15.0$ & $-15.3 / 20.5$ & $-9.8 / 18.2$ \\
\hline
\end{tabular}

The model prediction is stable for NMAX of 51 or greater. Increasing the number of nodes beyond 51 did not show much improvement. It is remarkable that even with NMAX of 11, the prediction degradation compared to NMAX of 401 is not significant.

\subsubsection{Influence of Choke Criterion}

The model prediction's sensitivity to choke condition was investigated in this section. The criterion used for the choke condition is; $\mathrm{dP} / \mathrm{dZ}$ at the throat of $-2.0 \times 10^{9} \mathrm{~Pa} / \mathrm{m}$ or below for the reference $\mathrm{V} \& \mathrm{~V}$ case. $\mathrm{dP} / \mathrm{dZ}$ value was varied from $-2.0 \times 10^{6}$ to $-2.0 \times 10^{15}$ to investigate the influence on the model prediction. The result is shown below.

Table 4.3: Prediction sensitivity to Choking Criterion

\begin{tabular}{|l|l|l|l|}
\hline & \multicolumn{3}{|c|}{ Bias/Standard Deviation (\%) } \\
\hline $\mathrm{dP} / \mathrm{dZ}$ & Subcooled & Saturated & Total \\
\hline$-2.0 \mathrm{E}+06$ & $-10.6 / 21.5$ & $-36.4 / 17.0$ & $-21.8 / 23.4$ \\
\hline$-2.0 \mathrm{E}+08$ & $-5.5 / 20.9$ & $-16.1 / 20.2$ & $-10.1 / 18.2$ \\
\hline$-2.0 \mathrm{E}+09$ & $-5.4 / 15.0$ & $-15.3 / 20.5$ & $-9.7 / 18.3$ \\
\hline$-2.0 \mathrm{E}+12$ & $-5.4 / 15.0$ & $-15.2 / 20.7$ & $-9.6 / 18.3$ \\
\hline$-2.0 \mathrm{E}+15$ & $-5.4 / 15.0$ & $-15.2 / 20.7$ & $-9.6 / 18.3$ \\
\hline
\end{tabular}

The sensitivity shown in Table 4.3 is consistent with the previous work. The exit $\mathrm{dP} / \mathrm{dZ}$ of approximately $-1.0 \times 10^{12}$ was used by Amos and Schrock (1984) and Lee and Schrock (1990). They reported that $\mathrm{dP} / \mathrm{dZ}$ below $-1.0 \times 10^{9}$ had negligible impact on the prediction which is what Table 4.3 indicates.

\subsubsection{Sensitivity to Initial Void Fraction}

In many Thermal-hydraulic systems codes, the minimum void fraction set to a positive non-zero value to preclude a singular matrix for the numerical computation reasons. It is then important to know the possible influence of the initial void fraction in the critical flow model since in these 
codes, even single phase liquid fluid cell would have a very small non-zero positive void fraction.

The model prediction's sensitivity to the minimum void fraction assumed in the critical flow module was investigated by varying the minimum value from 0.01 down to 0 . The result is shown below.

Table 4.4: Sensitivity to the initial void fraction

\begin{tabular}{|l|l|l|l|}
\hline & \multicolumn{3}{|l|}{ Bias/Standard Deviation (\%) } \\
\hline ALMIN & Subcooled & Saturated & Total \\
\hline \hline $1.0 \mathrm{E}-02$ & $-6.0 / 14.9$ & $-15.3 / 20.6$ & $-9.8 / 18.2$ \\
\hline $1.0 \mathrm{E}-03$ & $-5.7 / 15.0$ & $-15.3 / 20.6$ & $-9.8 / 18.2$ \\
\hline $1.0 \mathrm{E}-04$ & $-5.4 / 15.0$ & $-15.3 / 20.5$ & $-9.7 / 18.3$ \\
\hline $1.0 \mathrm{E}-08$ & $-5.3 / 15.0$ & $-15.3 / 20.5$ & $-9.6 / 18.3$ \\
\hline $1.0 \mathrm{E}-12$ & $-5.3 / 15.0$ & $-15.3 / 20.5$ & $-9.6 / 18.3$ \\
\hline $1.0 \mathrm{E}-15$ & $-4.2 / 18.1$ & $-15.3 / 20.5$ & $-9.0 / 19.9$ \\
\hline 0.0 & $-2.9 / 22.4$ & $-15.3 / 20.5$ & $-8.3 / 22.5$ \\
\hline
\end{tabular}

It is interesting to note that the model predictive performance degrades when there is no minimum void fraction cutoff. Based on the relaxation parameter defined in Eq. (5), If the initial void fraction is zero in subcooled region, and when liquid becomes superheated, the relaxation parameter is infinity and the vapor generation term in the governing equation would be zero. Thus when ALMIN, the minimum allowable void fraction, is set to zero, some predictions completely missed the data which is reflected as a substantial increase in standard deviation for $\mathrm{ALMIN}=0$ case.

\subsection{CONCLUSIONS}

HNRM critical flow model was assessed against selected data for Small Break LOCA analysis application. Against both small and full scale

HNRM Model Prediction vs. Marviken_6 Data

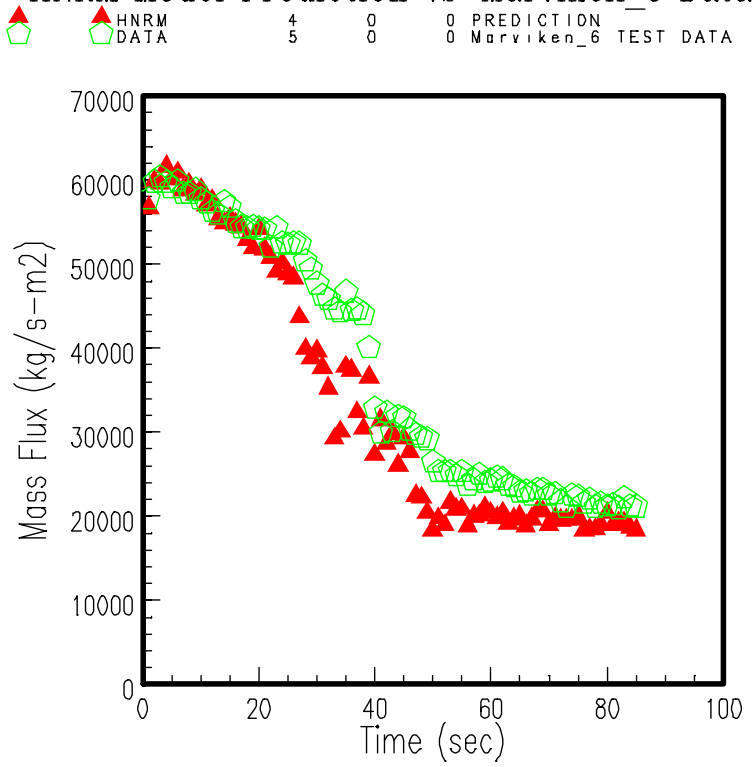

Figure 12: HNRM Applied to Marviken Test 6 tests, the model shows a smooth transition from subcooled to saturation as seen in Figure 12.

The mean error and standard deviation against a selected small and full scale dataset containing 1418 points were found to be $-9.7 \%$ and $18.2 \%$ respectively.

Parametric study was conducted to investigate the trend and stability of the predictions. The results indicated that there are minor trend relative to pressure while significant trends were found relative to L/D, L, and inlet quality. The model was found to be numerically stable (node size and choke criterion), however it appears to require that the flow quality to be non-zero and less than 1.

\subsection{REFERENCES}

Abuaf, N., Jones, O. C. Jr., and Wu, B. J. C. "Critical Flashing Flows in Nozzles with Subcooled Inlet Conditions," Journal of Heat Transfer, 105, 2, 379, pp 65-74, 1983.

Alamgir, M. D. and Lienhard, J. H. "Correlation of Pressure Undershoot During Hot-Water Depressurization," Transaction of the ASME, pp 52-55, Vol. 103, 1981.

Amos, C. N. and Schrock, V. E. "Critical Discharge of Initially Subcooled Water Through Slits," NUREG/CR-3475, 1983.

Anderson, J. L. and Benedetti, R. L. "Critical Flow through small pipe break," EPRI/NP-4532, May, 1986.

Ardron, K. H. \& Ackerman, M. C., "Studies of the critical flow of subcooled water in a pipe," CEGB Report: RD/B/N4299, 1978.

Bauer, E. G., Houdayer, G. R. and Sureau, H. M. "A Non-Equilibrium Axial Flow Model and Application to Loss of Coolant Accident Analysis: the CLYSTERE System Code," pp. 429-458, Proceedings of the CSNI Specialists Meeting, August, 1976, Toronto.

Bilicki, Z. and Kestin, J. "Physical aspects of relaxation model in two-phase flow," Proc. R. Soc. London, A428, 379-397, 1990.

Blinkov, V. N., Jones, O. C., and Nigmatulin, B. I. "Nucleation and Flashing in Nozzles-2: Comparison with experiments using a five-equation model for vapor void development," International Journal of Multiphase Flow, Vol. 19, No. 6, Pages 965-986, 1993.

Boivin, J. V., "Two-phase critical flow in long nozzles," Nuclear Technology, 46, pages 540-545, 1979.

Brown, W. L., Kemper, R. M., and Ohkawa, K. "SURVEY AND EVALUATION OF MODELS AND 
EXPERIMENTAL DATA BASES FOR SMALL BREAK BEST ESTIMATE (BE) LOCA," International Meeting on "Best-Estimate" Methods in Nuclear Installation Safety Analysis (BE-2000), Washington, DC, November, 2000.

Bryers, R. W., Hsieh, W. W., Hunter, J. A. \& Sieder, E. N., "Study of two-phase metastable flow," U. S. Department of Interior, Office of Saline Water, R\&D Progress Report No. 234, November, 1966.

Cruver, J. E., "Metastable critical flow of steam water mixtures," Ph. D. dissertation, Department of Chemical Engineering, University of Washington, 1963 (University Microfilms Inc., Ann Arbor, Michigan).

Danforth, J. L., "Flow of hot water through a rounded orifice," M. S. dissertation, Department of Mechanical Engineering, Massachusetts Institute of Technology, 1941.

Downar-Zapolski, P., Bilicki, Z., Bolle, L. and Franco, J. "The Non-equilibrium Relaxation Model for One-dimensional Flashing Liquid Flow," International Journal of Multiphase Flow, Vol. 22, No. 3, pp. 473-486, 1996.

Elias, E. and Lellouche, G. S. "Two-Phase Critical Flow," International Journal of Multiphase Flow, Volume 20, Supplement, pages 91-168, 1994.

Fauske, H. K., "Contribution to the theory of two-phase, one component critical flow," Argonne National Laboratory Report ANL-6633, 1962.

Feburie, V., Giot, M., Granger, S. and Seynhaeve, J. M. "A Model for Choked Flow Through Cracks with Inlet Subcooling," International Journal of Multiphase Flow, Vol. 19, No. 4, pp. 541-562, 1993.

Fincke, J. R. \& Collins, D. R., "The correlation of two-dimension and non-equilibrium effects in subcooled choked nozzle flow," NUREG/CR-1907, EGG-2081, 1981.

Guizovarn, L., Pinet, B., Barriere, G. \& Pietri, D., "Etude expermentale des debits critiques en ecoulement diphasiques eau vapeur a faible titre dans un canal avec divergent de $7 \times$ a des Transports Thermiques," Note TT No. 501, 1975.

Henry, R. E., "An experimental study of low quality, steam-water critical flow at moderate pressures," Argonne National Laboratory Report ANL-7740, 1970.

Henry, R. E. and Fauske, H. K., "Two-phase Critical Flow of One Component Mixtures in Nozzles, Orifices and Short Pipes," ASME Journal of Heat Transfer, 93, 1971.
Ilic, V., Banerjee, S. and Behling, S. "A Qualified Database for the Critical Flow of Water", EPRI-NP-4556, May, 1986.

Isbin, H. S., Moy, J. E. \& DuCruz, A. J. R., "Two-phase steam water critical flow," AIChE Journal, 3, September, 1957.

Jeandey, C., Gros D'Aillon, L., Bourgin, R. \& Barriere, G., "Auto vaporisation d'ecoulements eau/vapeur," Departement des Reacteurs a Eau Service des Transferts Thermiques (Centre D'Etudes Nucleaires de Grenoble) Report T. T. No. 163, 1981.

Jones, O. C., Jr., "Flashing Inception in Flowing Liquids,"Trans. ASME, J. Heat Transfer, Vol. 102, pp. 439-444, 1980.

Kroeger, P. G. "Application of a Non-Equilibrium Drift-Flux Model to Tow-Phase Blowdown Experiments," presented at OECD/NEA Specialists' Meeting on Transient Two-Phase Flow, Toronto, Canada, August 1978.

Lee, S. Y. and Schrock, V. E. "Critical Two-Phase Flow in Pipes for Subcooled Stagnation States with a Cavity Flooding Incipient Flashing Model," Transaction of the ASME, Vol. 112, pp. 1032-1040, November 1990.

Levy, S., "Steam Slip-Theoretical Prediction from Momentum Model," Journal of Heat Transfer, 82 (1960).

Morrison, A. F., "Blowdown flow in the BWR BDHT test apparatus," GEAP-21656, 1977.

Neusen, K. F., "Optimizing of flow parameters for the expansion of very low-quality steam," University of California, Lawrence Radiation Laboratory, UCRL-6152, 1969.

Ogasawara, H., "A theoretical approach to two-phase critical flow," 4th Report, experiments on saturated water discharging through long tubes," Bull. JSME 12 (52), 1969.

Reocreux, M., "Contribution a l'etude des debits critiques en ecoulement diphasique eau-vapeur," Doctral thesis a l'Universite Scientifique et Medicale de Grenoble, 1974.

Riznic, Jovica R. and Ishii, Mamoru, "Bubble number density and vapor generation in flashing flow," International Journal of Heat and Mass Transfer, Vol. 32, No. 10, Pages 1821-1833, 1989.

Seynhaeve, J. M., "Etude experimentale des ecoulements diphasiques critiques a faible titre," Doctoral thesis, Department Thermodynamique et Turbomachines, Universite Catholique de Louvain, 1980. 
Schrock, V. E., Starkman, E. S. \& Brown, R. A., "Flashing flow of initially subcooled water in convergent-divergent nozzles," Journal of Heat Transfer 99 (2), 1977.

Shin, T. S. and Jones, O. C. "Nucleation and Flashing in Nozzles-1: A Distributed Nucleation Model," International Journal of Multiphase Flow, Vol. 19, No. 6, Pages 943-964, 1993.

Sozzi, G. L. and Sutherland, W. A., 1975, "Critical Flow of Saturated and Subcooled Water at High Pressure," NEDO-13418.

Zaloudek, F. R., 1964, "Steam-Water Critical Flow From High Pressure Systems," HW-80535.

WCAP-12945-NP, "Code Qualification Document for Best Estimate LOCA Analysis, Volume 1: Models and Correlations", S. M. Bajorek, M. Y. Young, K. Takeuchi, K. Ohkawa, M. E. Nissley and S. I. Dederer, March 1998.

RELAP5 Code Development Team,

"RELAP5/MOD3.2," NUREG/CR-5535, 1995

TRAC-PF1/MOD2 Code Manual, NUREG/CR-5673, 1992.

"The Marviken Full-Scale Critical Flow Tests," EPRI-NP-2370, 1982. 